\title{
ACCESS TO HEALTH SERVICES IN TOCANTINS, FROM 2009 TO 2019.
}

Amanda Cristina de Souza Vieira', Bianca Borges Martins¹, Matheus Nascimento Duarte'1, Thiago de Moura Arruda1', Wglaison Paulo Araújo Sobral', Fabiana Cândida de Queiroz Santos Anjos', Priscila Ferreira Barbosa'1

${ }^{1}$ Universidade de Gurupi - Gurupi (TO), Brazil.

Objective: The aim of this study was to analyze the distribution of access to mammography services in the Tocantins in the eight health regions of the state. Methodology: We used the data from the Breast Cancer Information System regarding the number of mammograms performed according to the municipality, from 2009 to 2019. The data were grouped according to the health region of each municipality, analyzing the absolute frequency. A chi-square test was applied, analyzing the significant relationship $(\mathrm{p}<0.05)$ between the number of municipalities in the region and the number of tests performed. Results: Among the health regions, the Bico do Papagaio has a greater representation in the number of cities, with $17.2 \%$ $(\mathrm{n}=24)$, followed by the Cerrado Tocantins-Araguaia, with 16.5\% ( $\mathrm{n}=23)$. During the period, 91,059 mammograms were performed, with one region: 33.2\% ( $n=30,249)$ in the Capim Dourado; 19\% (n=17,307) in the Middle North Araguaia; $13 \%$ $(n=11,372)$ in the Ilha do Bananal; $11 \%(n=10,177)$ in the Bico do Papagaio; $8 \%(n=7,152)$ in the Cantão; 6.7\% (n=6,083) in the Southeast region; $6.6 \%(n=6,005)$ in the Cerrado Tocantins-Araguaia; and 2.5\% $(n=1,978)$ in the Amor Perfeito. There was a significant difference between the variables $(\mathrm{p}<0.05)$, where it is clear that the second smallest region in the number of municipalities, Capim Dourado (10\%), has the highest number of tests performed. Conclusion: The accelerated urbanization had, as one of its main consequences, an accentuation of social inequalities, such as which can be elucidated in the centralization of resources. The principle of equity in access to the examination is neglected once more examinations were performed in the region with less representation in the municipalities, but with the greater technological development. It is possible to see a demand for the development of public policies, in order to reduce the economic and social divergences that hinder health promotion.

Keywords: Mammography; Public Health; Health Equity. 